\title{
Localization of nonpalpable pulmonary nodules using CT-guided needle puncture
}

\author{
Hsian-He Hsu', Chih-Hao Shen², Wen-Chuan Tsai ${ }^{3}$, Kai-Hsiung Ko ${ }^{1}$, Shih-Chun Lee ${ }^{4}$, Hung Chang ${ }^{4}$
} and Tsai-Wang Huang ${ }^{4,5^{*}}$

\begin{abstract}
Background: Surgical resection of small pulmonary nodule is challenging via thoracoscopic procedure. We describe our experience of computed tomography (CT)-guided needle puncture localization of indeterminate pulmonary nodules prior to video-assisted thoracoscopic surgery (VATS).

Methods: From January 2011 to July 2014, 78 consecutive patients underwent CT-guided marking for the localization of 91 small pulmonary nodules. We retrospectively reviewed the clinical data, technical details, surgical findings and pathologic results, and complications associated with CT-guided localization.

Results: Seventy-eight consecutive patients (36 men and 42 women) underwent CT-guided marking localization of 91 indeterminate pulmonary nodules (62 pure ground-glass opacity nodules, 27 part-solid nodules, and 2 solid nodules). The mean size of the nodules was $8.6 \mathrm{~mm}(3.0-23.0 \mathrm{~mm})$. The mean pleural distance between the nodule and lung surface was $11.5 \mathrm{~mm}(3.0-31.3 \mathrm{~mm})$. The mean procedure time of CT-guided localization was $15.2 \mathrm{~min}$ (8-42 min). All patients stood the procedures well without requiring conversion to open thoracotomy. Twenty-four patients (30.77\%) developed pneumothorax after the procedures. Only one patient required retention of the puncture needle introducer for air drainage. The mean visual assessment pain score was 1.7 (0-3). Fifty-seven nodules (62.63\%) were confirmed as malignances, including 45 primary lung cancer, and 34 nodules (37.37\%) were confirmed as benign lesions.
\end{abstract}

Conclusions: CT-guided needle puncture can be an effective and safe procedure prior to VATS, enabling accurate resection and diagnosis of small pulmonary nodules.

\section{Background}

As the use of computed tomography (CT) becomes widespread in clinical practice, we have increasingly encountered small or faint lesions on CT [1]. Low-dose CT greatly increases the likelihood of detection of small nodules, and $51.7 \%$ of detected lung cancers found during baseline screening were ground-glass opacity (GGO) [2]. The accurate early diagnosis of these small nodules is challenging, even with dedicated CT, positron emission tomography-computed tomography (PET-CT), or image-guided percutaneous biopsy. Video-assisted thoracoscopic surgery (VATS) is a

\footnotetext{
* Correspondence: chi-wang@yahoo.com.tw

${ }^{4}$ Graduate Institute of Medical Science, Tri-Service General Hospital, National Defense Medical Center, Taipei, Taiwan

${ }^{5}$ Division of Thoracic Surgery, Department of Surgery, Tri-Service General Hospital, National Defense Medical Center, 325, Section 2, Cheng-Kung Road, Taipei 114, Taiwan

Full list of author information is available at the end of the article
}

minimally invasive surgery for management of lung nodules, both for curative resection and diagnostic procedures. One of the major problems often encountered during VATS is localization of the target nodule, which depends on its location, size, and characteristics such as nodule consistency. Further, when small nodules are located more than $2 \mathrm{~cm}$ below the pleural surface, it is difficult for the surgeon to determine their exact location during operation [3]. Failure to localize pulmonary nodules often results in the conversion of VATS to open thoracotomy. Conversion rates have been reported to be as high as $59 \%$ [4-6]. Several preoperative and intraoperative techniques have been described for nodule localization when performing VATS. These procedures include metallic hookwire localization under CT guidance [7], CT-guided micro-coil [8], a localization technique using barium [9-11], and intraoperative ultrasound [12]. However, most of these procedures have some limitations. Here, we 
present an alternative simple method, CT-guided needle puncture, for preoperative localization of pulmonary nodules before VATS.

\section{Methods}

This retrospective study was approved by our institutional review board of Tri-Service General Hospital (TSGHIRB No.: 1-103-05-126), and written informed consent was not required because of strict maintenance of patient anonymity and the observational nature of the study.

\section{Patients and procedures}

From January 2011 to July 2014, 78 consecutive patients with pulmonary nodules detected by CT scan (incidental findings, follow up because of previous malignancy, or underlying diseases) were included. Clinical parameters, including age, sex, smoking status, histology, and stage, were recorded for each patient. The characteristics of CT findings were recorded for each lesion: (a) lesion size, (b) location, (c) density, and (d) lesion distance from pleural distance (PD). All CT images were evaluated in consensus by two chest radiologists (H.H.H. and K.H.K., with 23 and 7 years of experience, respectively). Lesion size was defined as longest lesion dimension and was measured manually with electronic calipers on our picture archiving and communication system (PACS, EBM Technologies Incorporated, Taiwan). Each nodule was classified according to its density as pure nodular GGO, part solid, or solid pattern. GGO was defined as a hazy increase in lung density without obscuration of the underlying bronchial or vascular structures. A nodule was classified as part solid if it contained patches that completely obscured the lung parenchyma. We defined a solid nodule as a nodule that completely obscures the entire lung parenchyma within it.

Pulmonary nodules were followed with high-resolution CT over an interval of 3 to 6 months. Indications of tissue diagnosis for these patients included increasing nodule size, increasing soft tissue component, and underlying malignancy. Obtaining diagnostic tissue before surgery was difficult for all of these patients after consultation of radiology physicians. The nodules were not amenable for preoperative tissue diagnosis because of small lesion (less than $1 \mathrm{~cm}$ ), location (near the vessel), and patient's concern (refuse biopsy).

Preoperative studies included PET-CT, abdominal ultrasound, and cardiopulmonary function. All the patients gave informed consent before the procedures. The technical details, operative findings, and pathological features of nodules were evaluated.

The patient was transferred to the CT room before operation. A CT scan was performed to confirm the presence of nodules before the localization procedure. After $2 \%$ lidocaine local injection into the puncture site of the chest wall, the introducer for a 17-gauge puncture needle (Temno Coaxial Introducer Needle PP1910, CareFusion) was inserted under $\mathrm{CT}$ guidance. When the introducer was inserted into the lung parenchyma (Fig. 1a) (near the lesion, but without directly puncturing the lesion to avoid tumor seeding via a puncture tract), a CT scan confirmed the location of the introducer. The needle was then inserted via the introducer. All procedures were performed by experienced radiologists (H.H.H. and K.H.K.). Afterward, the patient was transferred to the operating room. Patient positioning and preparation were the same as standard VATS. All thoracoscopic procedures were performed under general anesthesia with selective intubation through a double lumen tube to obtain ipsilateral lung collapse. The patients were placed in a lateral decubitus position. In all patients, an $11.5-\mathrm{mm}$ trocar for thoracoscopy was inserted into the seventh intercostal space along the mid-axillary line. After an exploration of the pleural space, a second 11.5-mm trocar was placed according to the need for strategic visibility of the target lesion. After identification of the puncture holes (Fig. 1b), wedge resection of the target lesion was performed using an Endo-GIA $^{\mathrm{Tw}}$ Universal Stapler. The specimen was examined by a pathologist as a frozen section. The operations were terminated after the report of the pathological

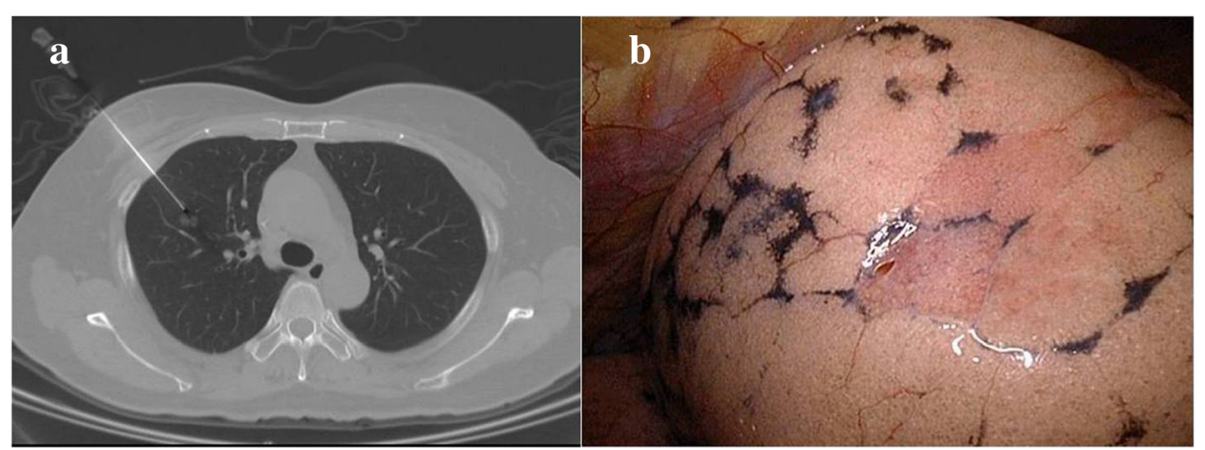

Fig. 1 a The puncture needle (Temno Coaxial Introducer Needle, Care Fusion, PP1910) was inserted under the CT-guided imaging. b Intraoperative identification of the puncture holes at lung surface after one lung ventilation 
results as benign lesions. For primary lung cancer, anatomic resection and mediastinal lymph node dissection were done. We evaluated the clinicopathological data, procedure-related parameters, and complications.

\section{Statistical analysis}

Data were entered into a spreadsheet program (Excel, Microsoft, Redmond, WA, USA). All analyses were performed using commercially available software (SPSS, version 12.2, 2004; SPSS, Chicago, IL, USA). The descriptive data were expressed as means \pm standard deviation. Student's $t$ test was used to analyze continuous variables. The $\chi^{2}$ test was used to compare categorical variables between groups. Results were regarded as significant when $p<0.05$.

\section{Results}

Seventy-eight consecutive patients (36 men and 42 women; mean age $57.24 \pm 9.40$ years) underwent CT-guided needle puncture for the localization of 91 pulmonary nodules (Table 1). Nine patients had more than one nodule (six patients had two nodules, two patient had three nodules, one patient had four nodules). Eleven patients had an underlying malignancy, and 2 patients had sarcoidosis. The

Table 1 Clinical and CT characteristics of 91 nodules in 78 patients

\begin{tabular}{ll}
\hline Variables & \\
\hline Male/female & $36 / 42$ \\
Mean age (years) & $57.24 \pm 9.40$ \\
Size (mm) & Mean, 8.6; range, 3.0-23.0 \\
$<10$ & $56(61.5)$ \\
$10-20$ & $32(35.2)$ \\
$\geq 20$ & $3(3.3)$ \\
Nodule from pleural distance (mm) & Mean, 11.5; range, 3.0-31.3 \\
$<10$ & $44(48.3)$ \\
$10-20$ & $34(37.4)$ \\
$\geq 20$ & $13(14.3)$ \\
Location & \\
RUL & $27(29.7)$ \\
RML & $5(5.5)$ \\
RLL & $16(17.6)$ \\
LUL & $25(27.4)$ \\
LLL & $18(19.8)$ \\
Nodule density & \\
Pure GGO & $62(68.1)$ \\
Part-solid & $27(29.7)$ \\
Solid & $2(2.2)$ \\
\hline
\end{tabular}

Numbers in parentheses are percentages

$R U L$ right upper lobe, $R M L$ right middle lobe, $R L L$ right lower lobe, $L U L$ left upper lobe, LLL left lower lobe, GGO ground-glass opacity nodules included 62 pure GGO nodules, 27 part-solid nodules, and 2 solid nodules. The mean size of the nodules was $8.6 \mathrm{~mm}$ (range, $3.0-23.0 \mathrm{~mm}$ ). The PD between the nodule and the lung surface was $11.5 \mathrm{~mm}$ (range, $3.0-31.3 \mathrm{~mm}$ ). The mean procedure time for CT-guided localization was $15.2 \mathrm{~min}$ (range, 8-42 min). Twenty-five nodules had more than one puncture. The mean visual assessment score of pain for the patients after the procedures was 1.7 $(0-3)$. All the patients tolerated the pain without any analgesics before surgery (Table 2). Twenty-four patients $(30.77 \%)$ developed pneumothorax after the procedures. There were no risk factors significantly associated with the occurrence of pneumothorax (Table 3). Only one patient $(1.28 \%)$ required retention of the puncture needle introducer for air drainage. There was no additional chest intubation. The patients were transferred to the operating room within $30 \mathrm{~min}$, and the VATS were performed within $1 \mathrm{~h}$ after CT-guided localization. There was no conversion to thoracotomy. The lesions were identified easily by locating the puncture hole after deflation of the lung. The identification of the puncture hole was achieved immediately during the VATS. Finger palpation of the specimen was done after wedge resection of the target lung parenchyma. After identification of the nodules, the specimens were sent to the pathological department for pathological examination. All nodules were diagnosed definitively (Table 4$)$. Fifty-seven nodules $(62.63 \%)$ were confirmed as malignancies, including 45 invasive adenocarcinoma, 7 minimally invasive adenocarcinoma, 3 atypical adenomatous hyperplasia, and 2 metastatic lesions. Thirty-four nodules $(37.37 \%)$ were confirmed as benign lesions, including 7 chronic granulomatous inflammation (three of these patients had underlying sarcoidosis), 1 harmatoma, and 1 sclerosing hemangioma. Forty-five patients who had confirmed diagnosis of invasive adenocarcinoma underwent lobectomy and lymph node dissection. The final pathological stages of these patients were stage IA.

\section{Discussion}

Lung cancer is the leading cause of cancer-related death worldwide. Early detection of lung cancer resulted in better prognosis. VATS is currently the preferred

Table 2 Procedure associated complications and results

\begin{tabular}{ll}
\hline CT-guided marking complications (rate) & $24(26.4 \%)$ \\
Asymptomatic pneumothorax & $23(29.49 \%)$ \\
Symptomatic pneumothorax & $1(1.28 \%)$ \\
Conversion to thoracotomy (rate) & 0 \\
Mean procedure time (minutes) & $15.2(8-42)$ \\
Needle puncture $>1$ & 25 \\
VAS pain score & $1.7(0-3)$
\end{tabular}

VAS visual assessment pain score 
Table 3 Possible risk factors for pneumothorax

\begin{tabular}{lll}
\hline Factor & OR $(95 \% \mathrm{Cl})$ & $p$ value \\
\hline Sex & $1.280(0.417-3.935)$ & 0.666 \\
Age $(>65$ years $)$ & $0.908(0.235-3.505)$ & 0.889 \\
Location & $0.861(0.275-2.680)$ & 0.476 \\
Puncture & $1.470(0.509-4.243)$ & 0.476 \\
Smoking & $1.375(0.257-7.353)$ & 0.710 \\
PD & $0.525(0.227-1.211)$ & 0.131 \\
\hline
\end{tabular}

$P D$ pleural distance

surgical procedure in dealing with lung tumor. Unfortunately, during thoracoscopic procedure, surgeons may have difficulty in detecting smaller and invisible nodules which were not palpable with endoscopic instruments. A conversion from VATS to thoracotomy is sometimes prescribed after failure to localize these lesions [9]. To reduce the rate of conversion to open surgery, several techniques have been developed to help the surgeon localize small nodules during thoracoscopic resection. The details of previous localization methods are summarized in Table 5 . In this study, we present an alternative simple method, CTguided needle puncture, for preoperative localization of pulmonary nodules before VATS procedures.

The most widely used technique is percutaneous hookwire placement. The hookwire technique showed a variable sensitivity (58 to $97.6 \%$ ) and a relatively high failure rate because of the dislodgment of the wire [13-15]. Radioactive technetium [16, 17] to localize pulmonary nodules could achieve high success rate, leading to flexible scheduling of the operation room (with $6 \mathrm{~h}$ half-life of radionuclide). However, the center must have the equipment and radiation protection to offer this procedure. The ultrasonography localization method offers a quick, more affordable, less invasive way of localizing lesions and high sensitivities of 92.6

Table 4 Histopathologic results of indeterminate nodules

\begin{tabular}{ll}
\hline Variables & $57(62.63)$ \\
\hline Malignancy (\%) & 45 \\
Adenocarcinoma, invasive & 7 \\
MIA & 3 \\
AAH & 2 \\
Metastasis & $34(37.36)$ \\
Benign (\%) & 7 \\
Fibrosis & 18 \\
Inflammation & 1 \\
Organized pneumonia & 1 \\
Harmatoma & 1 \\
Sclerosing hemangioma & 7 \\
Chronic granulomatous inflammation & 1 \\
\hline
\end{tabular}

MIA minimal invasive adenocarcinoma, $A A H$ atypical adenomatous hyperplasia
Table 5 Summary of localization procedures

\begin{tabular}{|c|c|c|c|}
\hline Method & Advantage & Disadvantage & Ref. \\
\hline \multirow[t]{2}{*}{$\begin{array}{l}\text { CT-guided } \\
\text { hookwire }\end{array}$} & Safe, fast & $\begin{array}{l}\text { Chest wall pain, } \\
\text { pneumothorax }\end{array}$ & \multirow[t]{2}{*}[7,13-15]{} \\
\hline & $\begin{array}{l}\text { Low complication } \\
\text { rate }\end{array}$ & Dislodgement & \\
\hline \multirow[t]{2}{*}{ CT-guided coil } & \multirow[t]{2}{*}{ Same as above } & $\begin{array}{l}\text { Lung parenchyma } \\
\text { damage }\end{array}$ & \multirow[t]{2}{*}[8]{} \\
\hline & & Coil migration & \\
\hline $\begin{array}{l}\text { CT-guided } \\
\text { barium spray }\end{array}$ & Same as above & $\begin{array}{l}\text { Inflammatory } \\
\text { reaction of tissue }\end{array}$ & [9-11] \\
\hline \multirow[t]{3}{*}{$\begin{array}{l}\text { Intraoperative } \\
\text { ultrasound }\end{array}$} & Quick & $\begin{array}{l}\text { Difficult for } \\
\text { emphysematous } \\
\text { lung }\end{array}$ & \multirow[t]{3}{*}[12,18,19]{} \\
\hline & More affordable & $\begin{array}{l}\text { For lesion more } \\
\text { than } 1 \mathrm{~cm}\end{array}$ & \\
\hline & Less invasive & $\begin{array}{l}\text { Operator } \\
\text { dependent }\end{array}$ & \\
\hline \multirow[t]{2}{*}{ Methylene blue } & Simple & \multirow{2}{*}{$\begin{array}{l}\text { Diffuse into } \\
\text { surrounding lung }\end{array}$} & \multirow[t]{2}{*}[19,20]{} \\
\hline & Inexpensive & & \\
\hline \multirow{3}{*}{$\begin{array}{l}\text { Fluoroscopic- } \\
\text { aided contrast } \\
\text { medium }\end{array}$} & \multirow{3}{*}{$\begin{array}{l}\text { Adequate margins } \\
\text { of resections on } \\
\text { fluoroscopic } \\
\text { imaging }\end{array}$} & Contrast allergy & \multirow[t]{3}{*}{ [21-23] } \\
\hline & & $\begin{array}{l}\text { Radiation } \\
\text { exposure }\end{array}$ & \\
\hline & & Pneumothorax & \\
\hline \multirow{3}{*}{$\begin{array}{l}\text { Radio-guided } \\
\text { thoracoscopic } \\
\text { surgery }\end{array}$} & \multirow[t]{3}{*}{$\begin{array}{l}\text { Real-time verifying } \\
\text { stapled margin }\end{array}$} & $\begin{array}{l}\text { Gamma ray } \\
\text { detector }\end{array}$ & \multirow[t]{3}{*}[24]{} \\
\hline & & $\begin{array}{l}\text { Diffusion or } \\
\text { pleural spillage }\end{array}$ & \\
\hline & & Short half-life & \\
\hline \multirow{4}{*}{$\begin{array}{l}\text { Bronchoscopic } \\
\text { metallic coil } \\
\text { marking }\end{array}$} & \multirow{4}{*}{$\begin{array}{l}\text { Avoid } \\
\text { pneumothorax, } \\
\text { secondary } \\
\text { hematoma, and } \\
\text { the intravascular } \\
\text { injection of } \\
\text { substances } \\
\text { originating in } \\
\text { needling }\end{array}$} & $\begin{array}{l}\text { Ultrathin } \\
\text { bronchoscope }\end{array}$ & \multirow[t]{4}{*}[25]{} \\
\hline & & C-arm use & \\
\hline & & Metallic allergy & \\
\hline & & $\begin{array}{l}\text { Coil migration, } \\
\text { cost }\end{array}$ & \\
\hline \multirow[t]{2}{*}{$\begin{array}{l}\text { CT-guided } \\
\text { puncture }\end{array}$} & $\begin{array}{l}\text { No dye, } \\
\text { radiotracer, or } \\
\text { contrast medium }\end{array}$ & $\begin{array}{l}\text { Cooperation with } \\
\text { radiologist }\end{array}$ & \multirow[t]{2}{*}{ This study } \\
\hline & No migration & $\begin{array}{l}\text { Technique } \\
\text { dependent }\end{array}$ & \\
\hline
\end{tabular}

Ref reference

to $100 \%[12,18,19]$. However, it is highly operator dependent and is limited by the emphysematous lungs. Methylene blue staining of the nodules provides an accurate method for localizing pulmonary nodules $[19,20]$. In some cases of methylene blue localization, a tendency to diffuse rapidly into the surrounding lung parenchyma after dye injection was observed $[19,20]$. It obstructed the use of this procedure. Fluoroscopic-aided resection using contrast media also yielded high success rates [21-23]. CT-guided percutaneous transthoracic barium localization can be an effective and convenient preoperative localization procedure. 
However, several studies have reported that barium can provoke a mild acute inflammatory and edematous reaction and may make the pathological diagnosis difficult [9-11]. Radio-guided localization of pulmonary nodules is a feasible and quick procedure with a high successful rate [24]. However, spillage to the pleural space can lead to a wider area of radioactivity, which reduces the precision of the resection. In addition, the requirement for use of intraoperative gamma probes and the potential harmfulness of the radiotracer may limit the application of this technique. CTguided bronchoscopic metallic coil marking might be a useful method for fluoroscopy-assisted thoracoscopic resection of pulmonary nodules [25]. The advantage of this procedure can avoid complications such as pneumothorax and hematoma because of transbronchial route administration of metallic coil. However, this technique may not be applicable for lesions near the hilum of the lung. It also resulted in coil migration. In addition, the cost of coil and ultra-thin bronchoscope is expensive.

In this study, we show that CT-guided needle puncture is a simple, alternative procedure for localization of pulmonary nodules before VATS. There is no requirement for involvement of additional facilities such as ultrasound, radiotracer, barium, or contrast injection. All of these nodules in our patients were detectable by CT-guided needle punctures. There was no instance of conversion to open thoracotomy. Initially, we used a 20-gauge needle, but in some patients, the puncture holes could only be found after careful inspection. In some patients, we indentified the puncture hole after inflation/deflation of the lung (air bubble emerged from the puncture hole). With accumulation of the experiences, the puncture hole could be visualized easily with use of 17-gauge needle. The occurrence of pneumothorax was not significantly different between different needle sizes. However, because of the small size of this study, verification of this relationship may require additional patient data. In our preliminary experiences, there was no life-threatening pneumothorax. It was no necessary to put chest tube even if development with symptomatic pneumothorax even if there is development of symptomatic pneumothorax. In addition, a small percentage of pneumothorax may provide the clue of precise puncture of lung parenchyma.

The location of nodule did not affect this procedure. The PD of the nodule did not affect the occurrence of pneumothorax. For deeper lesion, we often made more than one puncture for one lesion in the beginning of this study. However, there was no significant difference in the puncture number (one puncture hole group PD, $1.14 \pm 0.69 \mathrm{~mm}$; two puncture holes group PD, $1.15 \pm$ $0.81, p=0.99$ ). The location of the nodules (central or peripheral lesion) had no significant influence on the attempt of puncture number (Table 6). For deeper
Table 6 Comparison of one versus two punctures

\begin{tabular}{llll}
\hline Variables & $\begin{array}{l}\text { Single puncture group } \\
(n=66)\end{array}$ & $\begin{array}{l}\text { Two punctures group } \\
(n=25)\end{array}$ & $p$ value $^{*}$ \\
\hline $\begin{array}{l}\text { Age } \\
\text { (year) }\end{array}$ & $56.27 \pm 8.98$ & $59.80 \pm 10.19$ & 0.11 \\
PD $(\mathrm{cm})$ & $1.14 \pm 0.69$ & $1.15 \pm 0.81$ & 0.99 \\
Location & & \\
Central & 23 & 5 & 0.67 \\
Peripheral & 43 & 20 & \\
\hline * $<<0.05$ & &
\end{tabular}

nodules, it is possible to obtain two-dimensional localization when performing wedge resection of the lung parenchyma by using two punctures from different directions. This concept provides precise localization of nodules for VATS. In addition, pulmonary hemorrhage could result in pigmentation of the lung surface; this was useful in identification of the target lesion (Fig. 2). At initial practices, the patients were transferred to the operating room after localization procedures within half an hour. After that, we found that the puncture holes could still be identified even if the surgery was started $4 \mathrm{~h}$ later. With accumulation of more experiences, we propose that this procedure provides available time frame between labeling of nodule and surgery.

The advantage of this procedure is that the prelocalization CT scan can confirm the presence of nodules. Two patients avoided a VATS procedure after the pre-localization CT scan showed decreased size or disappearance of the lesion. This procedure is performed by radiologists and is very similar to the procedure for a CT-guided core needle biopsy, which most radiologists are very familiar, so that there was no additional learning curve or difficulty in performing this procedure. In addition, the procedure does not require additional facilities as do procedures such as radiotracer, contrast

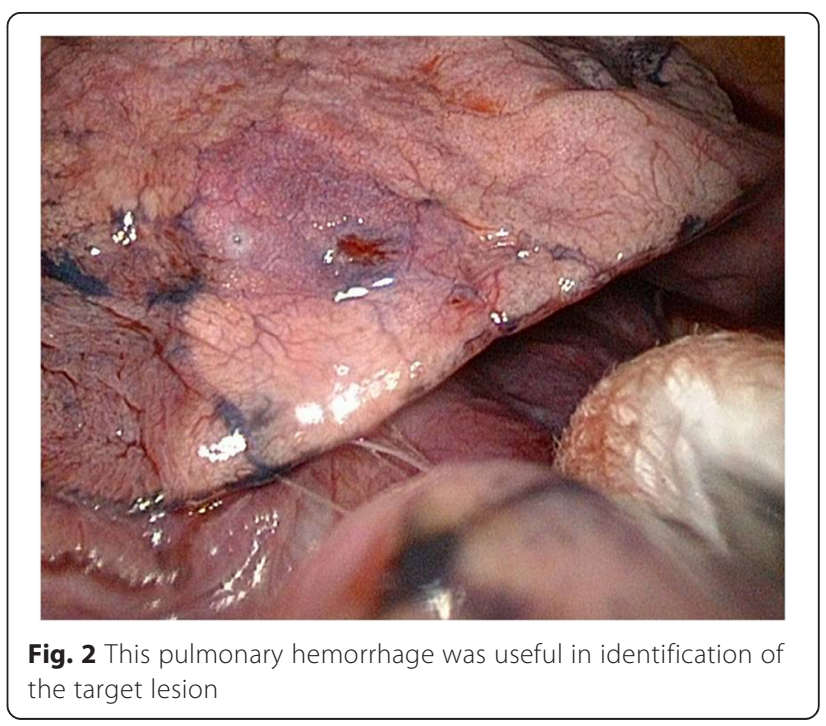


injection, coil insertion, or special ultrasound. There was no additional radiation exposure for the patients or physician during the operation and no necessity of a gamma probe to detection.

The limitations of this study are its small size and that it was a single-institution retrospective study. More convinced data should be obtained via including more patients and long-term follow-up. In addition, the cooperation of the radiologist and the use of available operating rooms are important. Prospective clinical trials of patients with indeterminate pulmonary nodules should be conducted to clarify the need for two punctures and the feasibility of using the technique for deeper lesions.

\section{Conclusions}

In conclusion, CT-guided needle puncture localization is feasible and simple for indeterminate pulmonary nodules before VATS. The procedure can result in a high success, low complications, and low cost without any additional facilities.

\section{Competing interests}

The authors declare that they have no competing interests.

\section{Authors' contributions}

$\mathrm{HHH}$ reviewed related literatures, participated in the sequence alignment, and drafted the manuscript. CHS and KHK collected patients' data, performed the statistical analysis, and drafted the manuscript. WCT reviewed patients' surgical specimens and was responsible for pathohistological diagnosis in all patients of our study. SCL and HC participated in the revision of the manuscript. TWH conceived of the study and participated in its design and coordination. All authors read and approved the final manuscript.

\section{Author details}

'Department of Radiology, Tri-Service General Hospital, National Defense Medical Center, Taipei, Taiwan. ${ }^{2}$ Department of Internal Medicine, Tri-Service General Hospital, National Defense Medical Center, Taipei, Taiwan. ${ }^{3}$ Department of Pathology, Tri-Service General Hospital, National Defense Medical Center, Taipei, Taiwan. ${ }^{4}$ Graduate Institute of Medical Science, Tri-Service General Hospital, National Defense Medical Center, Taipei, Taiwan. ${ }^{5}$ Division of Thoracic Surgery, Department of Surgery, Tri-Service General Hospital, National Defense Medical Center, 325, Section 2, Cheng-Kung Road, Taipei 114, Taiwan

Received: 12 April 2015 Accepted: 28 July 2015

Published online: 15 August 2015

\section{References}

1. Swensen SJ, Jett JR, Hartman TE, Midthun DE, Mandrekar SJ, Hillman SL, et al. CT screening for lung cancer: five-year prospective experience. Radiology. 2005;235:259-65.

2. Henschke CI, McCauley DI, Yankelevitz DF, Naidich DP, McGuinness G, Miettinen OS, et al. Early Lung Cancer Action Project: overall design and findings from baseline screening. Lancet. 1999;354:99-105.

3. Congregado M, Merchan RJ, Gallardo G, Ayarra J, Loscertales J. Video-assisted thoracic surgery (VATS) lobectomy: 13 years' experience. Surg Endosc. 2008:22:1852-7.

4. Powell TI, Jangra D, Clifton JC, Lara-Guerra H, Church N, English J, et al. Peripheral lung nodules: fluoroscopically guided video-assisted thoracoscopic resection after computed tomography-guided localization using platinum microcoils. Ann Surg. 2004;240:481-8.

5. Suzuki K, Nagai K, Yoshida J, Ohmatsu H, Takahashi K, Nishimura M, et al. Video-assisted thoracoscopic surgery for small indeterminate pulmonary nodules: indications for preoperative marking. Chest. 1999;115:563-8.
6. Cardillo G, Regal M, Sera F, Di Martino M, Carbone L, Facciolo F, et al. Videothoracoscopic management of the solitary pulmonary nodule: a single-institution study on 429 cases. Ann Thorac Surg. 2003;75:1607-11.

7. Chen S, Zhou J, Zhang J, Hu H, Luo X, Zhang Y, et al. Video-assisted thoracoscopic solitary pulmonary nodule resection after CT-guided hookwire localization: 43 cases report and literature review. Surg Endosc. 2011;25:1723-9.

8. Lizza N, Eucher P, Haxhe JP, De Wispelaere JF, Johnson PM, Delaunois L. Thoracoscopic resection of pulmonary nodules after computed tomographicguided coil labeling. Ann Thorac Surg. 2001;71:986-8.

9. Kobayashi T, Kaneko M, Kondo H, Nakayama H, Asamura H, Tsuchiya R, et al. CT- guided bronchoscopic barium marking for resection of a fluoroscopically invisible peripheral pulmonary lesion. Jpn J Clin Oncol. 1997;27:204-5

10. Okumura T, Kondo H, Suzuki K, Asamura H, Kobayashi T, Kaneko M, et al. Fluoroscopy-assisted thoracoscopic surgery after computed tomographyguided bronchoscopic barium marking. Ann Thorac Surg. 2001;71:439-42.

11. Asano F, Shindoh J, Shigemitsu K, Miya K, Abe T, Horiba M, et al. Ultrathin bronchoscopic barium marking with virtual bronchoscopic navigation for fluoroscopy-assisted thoracoscopic surgery. Chest. 2004;126:1687-93.

12. Khereba M, Ferraro P, Duranceau A, Martin J, Goudie E, Thiffault V, et al. Thoracoscopic localization of intraparenchymal pulmonary nodules using direct intracavitary thoracoscopic ultrasonography prevents conversion of VATS procedures to thoracotomy in selected patients. J Thorac Cardiovasc Surg. 2012;144:1160-5.

13. Gonfiotti A, Davini F, Vaggelli L, De Francisci A, Caldarella A, Gigli PM, et al. Thoracoscopic localization techniques for patients with solitary pulmonary nodule: hookwire versus radio-guided surgery. Eur J Cardiothorac Surg. 2007;32:843-7.

14. Bernard A. Resection of pulmonary nodules using video-assisted thoracic surgery. The Thorax Group. Ann Thorac Surg. 1996;61:202-4.

15. Mack MJ, Shennib H, Landreneau RJ, Hazelrigg SR. Techniques for localization of pulmonary nodules for thoracoscopic resection. J Thorac Cardiovasc Surg. 1993;106:550-3.

16. Burdine J, Joyce LD, Plunkett MB, Inampudi S, Kaye MG, Dunn DH. Feasibilily and value of video-assisted thoracoscopic surgery wedge excision of small pulmonary nodules in patients with malignancy. Chest. 2002;122:1467-70.

17. Chella A, Lucchi M, Ambrogi MC, Menconi G, Melfi FM, Gonfiotti A, et al. A pilot study of the role of TC-99 radionuclide in localization of pulmonary nodular lesions for thoracoscopic resection. Eur I Cardiothorac Surg. 2000;18:17-21.

18. Piolanti M, Coppola F, Papa S, Pilotti V, Mattioli S, Gavelli G. Ultrasonographic localization of occult pulmonary nodules during video-assisted thoracic surgery. Eur Radiol. 2003;13:2358-6.

19. Lenglinger FX, Schwarz CD, Artmann W. Localization of pulmonary nodules before thoracoscopic surgery: value of percutaneous staining with methylene blue. AJR Am J Roentgenol. 1994;163:297-300.

20. McConnell PI, Feola GP, Meyers RL. Methylene blue-stained autologous blood for needle localization and thoracoscopic resection of deep pulmonary nodules. J Pediatr Surg. 2002;37:1729-31.

21. Watanabe K, Nomori H, Ohtsuka T, Kaji M, Naruke T, Suemasu K. Usefulness and complications of computed tomography-guided lipiodol marking for fluoroscopy-assisted thoracoscopic resection of small pulmonary nodules: experience with 174 nodules. J Thorac Cardiovasc Surg. 2006;132:320-4.

22. Moon SW, Wang YP, Jo KH, Kwack MS, Kim SW, Kwon OK, et al. Fluoroscopyaided thoracoscopic resection of pulmonary nodule localized with contrast media. Ann Thorac Surg. 1999:68:1815-20.

23. Nomori H, Horio H, Naruke T, Suemasu K. Fluoroscopy-assisted thoracoscopic resection of lung nodules marked with lipiodol. Ann Thorac Surg. 2002;74:170-3.

24. Ambrogi MC, Melfi F, Zirafa C, Lucchi M, De Liperi A, Mariani G, et al. Radio-guided thoracoscopic surgery (RGTS) of small pulmonary nodules. Surg Endosc. 2012;26:914-9.

25. Toba H, Kondo K, Miyoshi T, Kajiura K, Yoshida M, Kawakami Y, et al. Fluoroscopy-assisted thoracoscopic resection after computed tomography-guided bronchoscopic metallic coil marking for small peripheral pulmonary lesions. Eur J Cardiothorac Surg. 2013;44:e126-32. 